\title{
Attitude, Skill, and Knowledge: (ASK) a New Model for Design Education
}

\author{
Ahmed A. Bakarman, $\mathrm{PhD}$ \\ Associated Professor, College of Architectural and Planning \\ King Saud University, \\ P. O. Box 57448 Riyadh 11574, Saudi Arabia, \\ bakarman@ksu.edu.sa
}

\begin{abstract}
Design education is a multi domain disciplines incorporate different aspects that as a whole aims to create a designer. Designer creation is not a simple task, and require, beside other aspects they have to obtain and acquire during their school years, students to have some aspects impeded in their personality,. Educator's role is to identify these aspects and direct their curriculum toward them. ASK, as an educational model, aims to identify them by decomposing design education discipline into manageable elements that reflect the main ingredients. The proposed ingredients are: professional attitude, design skills, and professional design knowledge. The main contribution of ASK is the ability to view this domain form a new perspective that is able to reflect the expectations of the professional.
\end{abstract}

\section{Introduction}

In architectural education the design education is the backbone [1], and the design studio is considered as "a milting pot" for this domain [2]. This type of education aims to prepare students for the professional practice and provide them with the required means to practice successfully. In order for design education to succeed in this manner, design educators have to direct their attention and efforts to the main ingredients of the design education discipline and have concentration.

This research argues that design education has three main components namely: attitude, skill, and knowledge, which are expressed in the model's acronym "ASK". And each one of them, with its inner components, prepares students to acquire and obtain different characters as means to produce a professional designer [3]. Each component of the ASK model devotes for specific purpose. As attitude refers to the behavior aspects that allow students to conduct themselves as designer, and to master the attitudes, either personal or professional that could eventually enable them to practice professionally. Skills refer to the design skills that enable students to carry out design problem architecturally. Finally, knowledge refers to the professional knowledge that allows students to think and act in a professional manner.

The contributions of ASK came from its ability to "milt" wide spectrums of aspects governing the design education into three well defined domains.

\section{Design Education:}

"In design school, students not only learn how to design, they are also introduced to a culture, various conceptions of design, and norms about what it means to be a designer. " [4]

This quotation summarized the whole argument of design education, and which type of modifications students faced and has to react to during the school years. Design education is not a passive education system but an active and interactive one, in which students get involved in all his/her self, as: soul, body, and mind [2]. Therefore, the transformation from a layperson to a designer is not an easy task and linear process. Students learn a life style, way of thinking, and style of reactions [5].

As design have different categories, such as: architecture, industrial, engineering, graphic, interior, product and others, each one has specific characters that distinguish them from other domain. Different researcher tried to identify the main ingredients of their educational system. Organizations such as ICSID for Industrial designer (2003) suggested that students have to be concentrated in their school years on three parts [3]:

1- Generic attributes: which include problem solving, communication skills, adaptability to rapid changes, etc.

2- Specific industrial design skills and knowledge: such as design thinking and design process, design methodologies, visualizing skills and knowledge, 
knowledge of product development process, manufacturing, materials and processes, design management, environmental awareness, model making, etc

3- Knowledge integration: which include strategies of system integration.

Even though these ingredients specific for industrial design, it may be applicable for other design discipline with some modification(s). in addition to that, and from these ingredients, we can notice that there is no clear cut and distinguish between the attitude and skills, in which some aspects mention earlier could be considered as skills and at the same time others may consider it as attitude and professional behavior. But at the end, students have to master them in comprehensive manner in order to conduct themselves as designer.

Beside these suggestions, we as educator, have to admit that various changes have occurred and they may require some modifications in our educational practice and curriculum. At the industrial design domain, there are certain changes and challenges that immerged and asked for modification in the education domain. These changes may be applicable to all design disciplines:

1- The emerging of a new technology creates the need to increase the use of digital media and influence the technique of sketching and rendering and model making beside the technical drawings.

2- There is no clear cut between the boundary of different design disciplines, which encourage designers to interact with other design discipline in order to understand it.

3- There is increasing need for team working not only with the traditional issue of physiology, materials and technology related to product development, but also to the user research and lifestyle.

4- The online resources are become essential and every body in the educational domain is dependent upon.

These changes, and others, which are applicable to architecture and design education highlight the importance of expanding our horizon at design education and cross the boundaries between different design disciplines.

\section{Design Studio}

Design studio, as main educational setting for different design disciplines, become as a "milting pot" for various aspects in design education. These aspects include skills, knowledge, and attitudes. This milting pot integrated all ingredients, and end up by exposing students to different disciplines. The importance of the design studio came from the type of relationship created between design tutor(s) and students, and the type of learning model, $\mathrm{i}$ e, learning by doing [2]. In this environment students try to practice design in a professional manner, and deal with different aspects in a professional way.

As mentioned earlier, students in school are not learning design only but also they are introduced to a "culture" of design and designer, design as discipline and designer as character. The studio culture allows students to think architecturally [2], and act in architecture manner [6]. In addition to that, this model of thinking and acting, in case student successes in acquiring and mastering, could distinguish his/her as designer from other profession [5].

\section{ASK's Ingredients}

After an overall introduction of the design education domain, it is the times to introduce ASK, as a new model for this type of professional education. The researcher, as a design tutor and an educator, believes that the importance of this model came from its holistic view in looking at design education ingredients from perspective of professional practice. At this perspective the model tries to sum up the basic expectations from any new graduate and explicit the required characters that can be measured and assessed. ASK aims to provide design educators, design students, and practitioners, who will recruit these graduates, with the means to identify and determine the assessment criteria for students/designer achievements.

The ingredients of ASK came from Vinke's (2002) definition of the competency as "the ability of an individual to select and use the knowledge, skills, and attitudes that are necessary for effective behavior in a specific professional, social or learning situation." These three components create the conceptual framework for ASK model and decomposed the design discipline into its essential parts and components as required by profession.

The following sections are devoted to explain and explore each ingredient in more details and identify their characters.

\subsection{Professional Attitude}

The professional attitude could be divided into two groups: personal and professional. At the first group students who aims to be a designer has to have personal attitude before being admitted to design school. While the second, students will master during the school years, in addition to that, it is the responsibility of design tutor to offer theme to their students. There are vast array of researches and viewpoints about this topic, and because of some limitation, we will list the most essential attitudes and behaviors that any design students have to obtain, either personal or professional. 


\subsubsection{Categories of professional behavior}

Lewis and Bonollo (2002) summarized the professional behavior into five categories as follow:

1- Negotiation with clients: which include task clarification.

2- Problem solving: as it is part of the professional skills, but designer has to have the attitude to solve design problem.

3- Accepting the responsibility for the outcome: which reflect the maturity of the designer.

4- Interpersonal skills: which reflect the ability to work in a group.

5- Project management: which mean organizing the task to meet the expected schedules and performance.

\subsubsection{Design student attitude}

Cross (2004) argued that the essential attitudes for design students to obtain are as follow:

1- The ability to gather the appropriate information to tackle design problem.

2- The ability of acquiring experiences, because the professional ability depends heavily on the amount of experiences students acquire.

3- The attitude of exposing students themselves to a vast majority of design problems and benefit the most from them.

4- Student has to be solution-approach in handling any design problem.

5- Negotiation with others, as clients and team member(s).

\section{4-1-3 Role of experience in designer attitude}

We can extract from these researches that one aspect student has to concentrate and acquire during their school years, it is the professional experience. The professional experience has the ability to shape student professional behavior, and how s/he approach design problem. Experiences could be acquired by different attitude such as: "motivation, concentration, and willingness to work hard on improving performance" [10].

Professional experience is not number of working years or projects, but it is a specific attitude and skills that expert designers utilized in order to complete the design task successfully. The amount of experience could effect the designer attitude toward solving a design problem, which provide then with a technique to handle design task, for example, novices behavior are usually associated with a " depth-first" approach that approach the design problem by exploring sub-solution in depth, while the expert could utilize the strategies of top-down and breadth-first approaches [9].
In order for student to gain and acquire different types of experiences that at the end could effected their professional behavior they have to expose themselves to a large number of problems and solutions [9]. The attitude of exposing to different type of problems and solution has to be a habit of each design student.

In general, being an expert designer govern the behavior toward solving a design problem, one of these behavior as Cross (2003) argues is: "Expert designers appears to be "ill-behavior" problem solver, especially in term of the time and attention they spend on defining the problem". To be ill-behave means you are not over concentrate on the problem definition which usually leads to unsuccessful design outcome. As a result, a successful design behavior is based not on overdone problem analysis, but on "problem scoping and on a focused or directed approach to gathering problem information and prioritizing criteria".

Another professional behavior that are related with the problem definition is the one that distinguish designer from layperson, which is the attitude of approaching design task. Lawson (1997) argues that designer is a "solution- focused" and not "problemfocused" in dealing with a design problem. This means that the designer approaches design problem not by trying to fully understand the problem and then propose a solution, but by proposing a solution in "principle" as a means to understand the design problem.

Therefore, students of design has to have the habit to generate a wide rang of alternatives as a means to improve their design practice and the design outcome besides their understanding of the design problem in hand. Generating many design alternatives is a good attitude for design students, as suggested by many design tutors, but it is not normal practice for expert designer, because they prefer to work from the early stages with a single early solution concept [9].

In sum, the professional attitude that design student has to accumulate could be listed as follow:

1- Expert behavior in dealing and handling the design problem.

2- Dedication and motivation to be good designer.

3- Knowledge acquisition and managing them.

4- Team work and the ability to run the task smoothly.

5- Time management.

6- Responsibility of the out comes.

\section{4-2 Design Skills}

Design disciplines have common skills which are shared among them, and each one is distinguished by some specific skills that reflect the nature of their design problem. The design problems faced by architect are not identical to that faced by industrial designer, but determining the "architectural design skills" could be extracted also from other design discipline such as 
Industrial design. In which the ICSID list mention earlier could help at this manner.

In addition to that, Yang et al (2005) argued that design students have to master the following skills, and design educators have to concentrate on these in the curriculum. The applicable skills are:

1- Design thinking and design process: in which students has to know the nature of the design thinking and the process, besides knowing how to go through and manage the process with skillful manner to reach the acceptable result. Knowing the design process is part of the design skills because it allow designer to understand many cognitive and mental aspects face designer during the design practice and deal with them professionally [11] [5].

2- Visualizing skills: this skills allow students imagine and create an image about the design problem as a whole at early stage of the deign process; mastering this skill allow expert designers to consider the design solution in principle at early stages and drive the design process toward the desirable end [9].

3- Design Management: this skill could incorporate different professional skills. Therefore, managing the design action, and dealing with the different partners in the design practice, beside the communication skills with others are essential skills. The most important part of the design management is the "acceptance of responsibility for the outcomes" [3], which reflects the awareness of designer during the design practice.

In addition, Lewis and Bonollo (2002) argued that the design skills are vast and could be summarized as follow:

1- Skills in task clarification.

2- Skills in concept generation.

3- Skills in evaluation and refinement.

4- Skills in detailing design.

5- Skills in communication of results.

6- Overall skill displayed in execution of process.

\section{4-3 Professional Design Knowledge}

The professional knowledge is considered as a fuel for designer from which s/he pulls out the seed for professional design decisions [5]. The professional knowledge is the means that guide designer to the desirable problem solution and it's the essence the professionalism [12].

To decompose the professional design knowledge into manageable ingredient in order to understand it and utilize it by the ASK model, we have to expand our horizon to many researches conducted to explore the issue of professional knowledge and mainly the design knowledge.
Carrera et al (1994) argued that the design knowledge is not a homogenous entity but it comprises several kinds of knowledge, in which they could be categorized as follow:

1- Descriptive Knowledge: this type of knowledge represents the object being designed and its performance.

2- Normative Knowledge: it represents the goals and constrains the designed object has to achieve and fulfill.

3- Operational Knowledge: it represents the strategies that are being used to select or generate objects, and how designer predicts their expected performance and evaluate them.

Decomposing the design knowledge into three categories (descriptive, normative, and operational) reflects the inner components of the design knowledge, which represent one viewpoint, while, other researchers decomposed it into two type based on the degree "to which knowledge can exist independently of a specific context or knower" [13] [14].

Polany (1964) divided the knowledge into:

1- Tacit Knowledge: This type of knowledge is impeded in the knower and its acquisition tends to be staggered over time and rooted in experiences.

2- Explicit Knowledge: It's a theoretical and academic knowledge which easily migrate from one knower to another.

The tacit knowledge is an important ingredient of any professional knowledge because it's the bases of professional experiences, and personal development [14]. Therefore, we have to highlight the mode of knowing and how learner acquired the professional knowledge [2].

As ASK is an educational model, the important of exploring how knowledge is created, and when the information become knowledge is essential. Design knowledge is the highest level of information, in order for it to be created; designer has to get involve in a real experience, as Kolb (1984) defined the learning as "the process whereby knowledge is created through the transformation of experience". As a result, there are wide agreements that "knowledge creation requires experience" [14].

Based on that we can identify the differences between information and data, and the knowledge, in which the formers are "external to and independent of the learner".

Another categorizing of the design knowledge is based on how and when designer utilize these knowledge, and the characters of these knowledge which reflect the nature of designers [16]. The first category is the "procedural", which refers to the type of knowledge that enable designer to conduct design, and purse it in a sophisticated and professional manner. The 
second category is the "declarative" which is a collection of knowledge about function, material, shapes and non-technical aspects of design (economic, social, juridical, etc.) [16]. In addition to the two categories, there are a third category related to the norms of product of the design and knowledge needed for team work. The third one is the "normative knowledge" which reflects the type on knowledge needed to describe the characters of the designed element and specifications. This category is the collaborative knowledge that refers to the knowledge related to design work in a group [17].

The distinguish between the first two types (procedural and declarative) is that the former is guiding design through the design process, while the later is about feeding the process with the essential knowledge for professional practice. The procedural or experiential knowledge refers to the type of knowledge which is impeded in designer and reflected in the amount of experiences $\mathrm{s} /$ he acquire and could utilize during the design practice. The declarative or the theoretical knowledge is essential for designer to accumulate and acquire to accomplish the design task [18].

In addition to the characters of each type, each one has significant role in building designer characters, in which the experimental knowledge creates the designer's sense and allow him/her to decide what to do next, while the theoretical knowledge allows designer to conduct design in a professional manner [2].

\section{ASK as a Design Educational Model}

After exploring the domain and the ingredients of the ASK model, it is the time to highlight the importance of the new model by explaining its potential usage and the possibility in utilizing the model at various stages of design education.

The researcher beliefs that the advantage of ASK not only in decomposing the discipline of design education into manageable ingredients, but also in composing different aspects that govern design education and classify them under three categories: attitude, skills, and knowledge. These categories reflect the essence of design education and have the ability to re-name different components of the discipline and combined them under specific titles.

Beside the ability to re-direct the focal point of the design education, the main usage of ASK is in the assessment of students achievements [19]. Design educators could utilize the model as assessment tool for various purposes in the cycle of design education. For this research, we will discuss the potential of ASK as assessment tool for students and professional achievements at three stages: before, during, and after school.

\subsection{ASK as a model for formulating an aptitude test for architectural school}

One of the debatable issues for school of architectural is the aptitude test as administration criteria for selecting students to be an architect. Selecting students for architecture profession has been explored and investigated by different researchers, and it became a problematic aspect [20] [21] [22]. For this research, ASK could provide us with some hints on which aspect we have to concentrate on in formulating and designing the test. For ASK, the most important aspect is assurance that new comers to architectural profession has the ability and could master the following:

- Attitudes: for students to be eligible to study architecture, and become an architect they have to own specific characters that make them ready for the new profession, such as patient, commitment, and ability to communicate.

- Skills: ASK could determine a limited number of skills students have and master even in a primitive manner, which will be developed in school. The skill could include visual, freehand, and analytical ability.

- Knowledge: this aspect could be omitted or underscored because student will be introduced to new discipline with specific knowledge, and they will be directed to explore the domain and acquire its specific knowledge. But ASK may focus on the nature of the profession and the level of student's understanding about it.

These aspects could be used to formulate an aptitude test and researcher started this experiment and wishes to present its result(s) in the near future.

\subsection{ASK as an assessment tool for students achievements}

Assessing student's achievement is a dilemma by itself, because there are different perspectives toward this aspect and about "what to assess" [19]. ASK model could propose a frame work for such assessment. In which the three components of the model could allow educators to concentrate on them, and evaluate student's achievements accordingly.

The professional attitude could be assessed and captured by design tutor during the semester, and design tutor could explain, in explicit manner, his/her personal view about student behavior. Assessing the design process could reveal student's professional and personal behavior, and allow design educators to decide if students eligible to pass. While, the second component, the design skill is an ordinary task to assess, in which educator could identify the students ability to 
be designer by assessing the end product, and the how student reach this end by monitoring them during the design process stage. Finally, the last part of ASK is the professional knowledge that could be assess either by the regular tool, i e exam, or by assessing the design product which show if students actually implement the provided knowledge in his/her design or not.

\subsection{ASK as a tool for graduate achievements or professional capabilities}

After graduation, professional society aims to control the quality of practice of the members, and protect its profession by allowing good individual to joint them. As these societies have long heritage in controlling over the new comers, researcher belief that the ASK model could help in this manner and cast the shadow in building a roadmap for effective professional design capabilities.

\section{Conclusion}

The driven forces behind generating ASK model, as design educational model, was to propose a new framework for design education. This framework rename different aspects in design education, which were segmented and segregated due to the wide rang of intervenes and additives by different researchers. The ingredients of the model reflected the vast array of aspects which govern the design discipline and "milting" them into one model. ASK could introduces us, as educators, to a new era of organizing the design education, as the case in design process when designer converts from the divergent mode to the convergent mode of thinking [23].

\section{References}

1- A. Salama, "A Voice for an alternative architectural education: integrating "What" and "How" knowledge" ARCHITTIMES, Karachi, Pakistan, September (2003).

2- A. Bakarman, "Architectural Learning Tool". Unpublished PhD thesis, the University of Sheffield, Sheffield, UK, (2002).

3- M. Yang, M. You and F. Chen "Competencies and qualifications for industrial design jobs: implications for design practice, education, and student career guidance" Design Studies, Vol. 26, Elsevier Ltd, UK, (2005), 155189.

4- B. Eyikan, "The making of a designer: convictions about skills and professional role in design". In the proceeding of "Forum II: architectural education for the $3^{\text {rd }}$ millennium" Eastern Mediterranean University and Istanbul Technical University, Turkey, (1998), 379-389.

5- B. Lawson, "How designers think: the design process demystified", Butterworth Architecture, Oxford, UK, (1997).
6- N. Cross, "Designerly ways of knowing." Design Studies, Vol. 3, Elsevier Ltd, UK, (1982), 221-227.

7- D. Vinke, Industrial design at TU/e: the student as a junior employee, Interim report, retrieved September 15, 2003 from the world wide: www.industrialdesign.tue.nl/education/ downloadableFiles/theStudentAsAJuniorEmployee.doc

8- W. Lewis, and E. Bonollo, "An analysis of professional skills in design: implications for education and research", Design Studies, Vol. 23, Elsevier Ltd, UK, (2002), 385406.

9- N. Cross, "Expertise in design: an overview" Design Studies, Vol. 25, Elsevier Ltd, UK, (2005), 427-441.

10- K. Ericsson, "Attaining excellence through deliberate practice: insights from the study of expert performance" in M Ferrari (ed.). The Pursuit of excellence through education, Erlbaum, Hillsdale, NJ, USA (2001)

11- A. Sachs "'Stuckness' in the design studio." Design Studies, Vol. 20, Elsevier Ltd, UK, (1999), 195-209.

12- G. Carrara, and Y. Kalay, "Past, present, future: process and knowledge in architectural design" in G. Carrara, and Y. Kalay (ed.) knowledge-based. Computer-aided architectural design, Elsevier, Amsterdam Chandrasekaran, (1991).

13- M. Polanyi, "Personal knowledge", Harper and Row, New York, NY (1964).

14- K. Friedman, "Creating design knowledge: From research into practice", In the Proceeding of IDATER 2001, by E. Norman, and P. Roberts (eds.) department of design and technology, Loughborough University, UK, (2001).

15- D. Kolb, "Experiential Learning: Experience as The Source of Learning and Development", Prentice-Hall, New Jersey, (1984).

16- R. Broens, and M. Vries, "Classifying technological knowledge for presentation to mechanical engineering designers", Design Studies, Vol. 24, Elsevier Ltd, UK, (2003), 457-471.

17- N. Bayazit, "Designing: design knowledge, design research, related sciences" in M. Vries, N. Cross, and D. Grant (eds.) Design methodology and relationships with science, Kluwer Academic Publishers, Dordrecht (1993), 121-136.

18- A. Heylighen, H. Neuckermans, and J. Bouwen, "Walking on a thin line - Between passive knowledge and active knowing of components and concepts in architectural design." Design Studies, Vol. 20, Elsevier Ltd, UK, (1999). 211-235.

19- A. Bakarman "Quality Evaluation Tool for the Design Studio Practice: A theoretical background". In the Proceeding of the $6^{\text {th }}$ Asian Design international Conference: Integration of Knowledge, Kansai, and Industrial Power. Tsukuba, Japan, (2003).

20- A. Izadi, "Student selection criteria for the study of architecture with special reference to Iran", Unpublished $\mathrm{PhD}$ thesis, the University of Sheffield, Sheffield, UK, (2002).

21- K. Al-Saud, "Admission measures in the college of architecture and planning as an indicator of the academic success" Journal of King Saud University, Vol. 12, King Saud University, Saudi Arabia, (2000), 81-112. 
22- G. Goldschmidt, R. Sebba, C. Oren, and A. Cohen, "Who should be a Designer? Controlling admission into schools of architecture". In the Proceeding of "the 5ht Design thinking research symposium: Designing in Context" by H. Christiaans, and P. LIoyd (eds.), Delft University of Technology, The Netherlands, (2001).

23- Y. Liu, T. Bligh, and A. Chakrabarti, "Toward an 'ideal' approach for concept generation” Design Studies, Vol. 24, Elsevier Ltd, UK, (2003). 341-355. 